\title{
Predictive factors of clinical assays on hydroxychloroquine for COVID-19 mortality during the first year of the pandemic: a meta-synthesis
}

\author{
${ }^{* 1,2}$ Million, M., 1,2Dudouet, P., 1,2Chabriere, E., ${ }^{1,3}$ Cortaredona, S., 1,2Roussel, Y., \\ ${ }^{1,2}$ Brouqui, P., and ${ }^{1,2}$ Raoult, D. \\ ${ }^{1}$ IHU-Méditerranée Infection, Marseille, France \\ ${ }^{2}$ Aix Marseille Univ., IRD, AP-HM, MEPHI, Marseille, France \\ ${ }^{3}$ Aix Marseille Univ., IRD, AP-HM, SSA, VITROME, Marseille, France \\ *Correspondence to: Prof. Matthieu Million. MEPHI, Institut Hospitalo-Universitaire Méditerranée Infection, 19-21 Boulevard \\ Jean Moulin 13385 Marseille Cedex 05, France. \\ E-mail: matthieumillion@gmail.com; Phone: + 33 (0) 4137324 01; Fax: + 33 (0) 413732402
}

\begin{abstract}
:
Background: The COVID-19 pandemic led to a violent debate about the efficacy of a repurposed drug hydroxychloroquine (HCQ) and a new broad-spectrum antiviral (remdesivir) and about randomized controlled trials (RCTs) and observational studies. To understand conflicting results in the literature, we performed a metasynthesis to determine whether intrinsic qualitative criteria within studies may predict apparent efficacy or ineffectiveness of HCQ and remdesivir.

Methodology: Predictive criteria were identified through critical review of studies assessing HCQ and remdesivir for COVID-19 mortality from March to November 2020. Multiple correspondence analysis, comparative metaanalysis, and predictive value were used to explore and identify criteria associated with study outcomes.

Results: Among the 61 included studies, potential conflict of interest, detailed therapeutic protocol, toxic treatment (overdose or use in contraindicated patients), known centers and doctors, and private data computing company were the most predictive criteria of the direction of effect of the studies. All 18 observational studies evaluating HCQ and reporting detailed therapeutic protocol without conflict of interest were Pro. Potential conflict of interest was a perfect predictor for remdesivir efficacy. RCTs were associated with HCQ inefficacy and potential conflict of interest. The most predictive criteria were validated and allowed perfect classification of 10 additional studies.

Conclusion: In therapeutic trials on COVID-19, the major biases predicting the conclusions are not methodology nor data analysis, but conflict of interest and absence of medical expertise. The thorough search for declared or undeclared and direct or indirect conflict of interest, and medical expertise should be included in the quality criteria for the evaluation of future therapeutic studies in COVID-19 and beyond. A new checklist evaluating not only methodology but also conflict of interest and medical expertise is proposed.
\end{abstract}

Keywords: COVID-19; Hydroxychloroquine; Remdesivir; Meta-analysis; Conflict of interest; Clinical expertise; Methodology; Simpson's paradox effect; Checklist

Received Dec 3, 2021; Revised Dec 29, 2021; Accepted Dec 30, 2021; Published online Jan 18, 2022

Copyright 2022 AJCEM Open Access. This article is licensed and distributed under the terms of the Creative Commons Attrition 4.0 International License <a rel="license" href="http://creativecommons.org/licenses/by/4.0/", which permits unrestricted use, distribution and reproduction in any medium, provided credit is given to the original author(s) and the source. Editor-in-Chief: Prof. S. S. Taiwo

\section{Facteurs prédictifs des tests cliniques sur l'hydroxychloroquine pour la mortalité du COVID-19 au cours de la première année de la pandémie: une méta-synthèse}

\footnotetext{
${ }^{* 1,2}$ Million, M., ${ }^{1,2}$ Dudouet, P., ${ }^{1,2}$ Chabriere, E., ${ }^{1,3}$ Cortaredona, S., ${ }^{1,2}$ Roussel, Y., ${ }^{1,2}$ Brouqui, P., et ${ }^{1,2}$ Raoult, D.
}

${ }^{1}$ IHU-Méditerranée Infection, Marseille, France

${ }^{2}$ Aix Marseille Univ., IRD, AP-HM, MEPHI, Marseille, France

${ }^{3}$ Aix Marseille Univ., IRD, AP-HM, SSA, VITROME, Marseille, France

*Correspondance à: Prof. Matthieu Million. MEPHI, Institut Hospitalo-Universitaire Méditerranée Infection, 19-21 Boulevard Jean Moulin 13385 Marseille Cedex 05, France.

E-mail: matthieumillion@gmail.com; Phone: + 33 (0) 4137324 01; Fax: + 33 (0) 413732402 


\section{Résumé:}

Contexte: La pandémie de COVID-19 a conduit à un violent débat sur l'efficacité d'un médicament réutilisé, l'hydroxychloroquine (HCQ) et un nouvel antiviral à large spectre (remdesivir) et sur les essais contrôlés randomisés (ECR) et les études observationnelles. Pour comprendre les résultats contradictoires de la littérature, nous avons effectué une méta-synthèse pour déterminer si les critères qualitatifs intrinsèques des études peuvent prédire l'efficacité ou l'inefficacité apparente de l'HCQ et du remdesivir.

Méthodologie: Des critères prédictifs ont été identifiés grâce à un examen critique des études évaluant I'HCQ et le remdesivir pour la mortalité due au COVID-19 de mars à novembre 2020. Une analyse des correspondances multiples, une méta-analyse comparative et une valeur prédictive ont été utilisées pour explorer et identifier les critères associés aux résultats de l'étude.

Résultats: Parmi les 61 études incluses, les conflits d'intérêts potentiels, le protocole thérapeutique détaillé, le traitement toxique (surdosage ou utilisation chez des patients contre-indiqués), les centres et médecins connus et la société informatique privée étaient les critères les plus prédictifs de la direction de l'effet des études. Les 18 études observationnelles évaluant I'HCQ et rapportant un protocole thérapeutique détaillé sans conflit d'intérêt étaient Pro. Un conflit d'intérêts potentiel était un prédicteur parfait de l'efficacité du remdesivir. Les essais randomisés étaient associés à l'inefficacité des HCQ et à un conflit d'intérêts potentiel. Les critères les plus prédictifs ont été validés et ont permis une classification parfaite de 10 études supplémentaires.

Conclusion: Dans les essais thérapeutiques sur COVID-19, les principaux biais prédisant les conclusions ne sont pas la méthodologie ni l'analyse des données, mais le conflit d'intérêts et l'absence d'expertise médicale. La recherche approfondie des conflits d'intérêts déclarés ou non, directs ou indirects et de l'expertise médicale doit être incluse dans les critères de qualité pour l'évaluation des futures études thérapeutiques dans le COVID-19 et au-delà. Une nouvelle liste de contrôle évaluant non seulement la méthodologie mais aussi les conflits d'intérêts et l'expertise médicale est proposée.

Mots-clés: COVID-19; Hydroxychloroquine; Remdesivir; Méta-analyse; Conflit d'intérêt; Expertise clinique; Méthodologie; L'effet paradoxe de Simpson; Liste de contrôle

\section{Introduction:}

In the COVID-19 episode, one of the greatest scientific scandals of all time occurred (1) with the rapid retractions of two major publications in most famous journals $(2,3)$. In the meantime, a considerable debate has emerged on a broad-spectrum antiviral drug candidate recently developed by a biopharmaceutical company, which was finally considered ineffective in lowering mortality among hospitalized patients with COVID-19 (4), a few days after the European Commission purchased two billion Euros worth of this drug. The putative efficacy of this drug was mainly published in the most famous medical journals, some of whose articles were only small noncomparative series $(5,6)$. On the other hand, more than 180 publications have been made on hydroxychloroquine (HCQ), with censorship effects such as refusal to examine the publications, including ours (7), even though it was the largest mono-centric series in the world. All publications showing a positive effect of HCQ have been published in journals that until then were not the scientific leaders in the field. All this was done in an unprecedented financial context, since the broad-spectrum antiviral drug candidate, whose futility was finally shown (4), was the subject of unprecedented speculation on a pharmaceutical product and therefore the financial stakes were colossal (1, 6).

Furthermore, conflicts of interest at all levels have been neglected; that of the government, politicians, scientific advisors, appointtees (5), and that of the journals and the publishers themselves, whose funding is often common with that of the pharmaceutical indu- stry, and who receive advertising from the pharmaceutical industry $(1,5)$. Conflicts of interest of authors are often neglected, without being penalized in scientific journals, despite the evidence of bias $(8,9)$. Finally, conflicts of interest of reviewers are neglected, given that the milieu of people who conduct therapeutic trials is very commonly affected by conflicts of interest, as shown for infectious disease academics (9).

In this context, an objective analysis of published data requires the establishment of new criteria, which are independent of these pressures, in order to have certain reliability. The absence of such criteria leads to variability in meta-analyses $(10,11)$. Finally, quantitative meta-analysis, and apparently therapeutic trial specialists, take less account of current medical practice and care, and the risk of bias related to pharmaceutical company influence, but rather focus on methodologies commonly recommended by pharmaceutical companies. For instance, randomized control trials (RCTs) are not superior to observational studies (12, 13) so that there is no transcendental methodology in therapeutic trials. Multicentric RCTs only reflect one perspective, which is not universal $(12,13)$, and which is more in line with the needs of the pharmaceutical industry than with the reality of practice, including in episodes of acute infection epidemics.

Overall, it seemed essential to list all the evaluation criteria for scientific studies, whether comparative, randomized or not, to assess their quality not from a medical-political point of view (5), and to consider the classifications obtained, depending on whether certain criteria are retained or excluded. The basic elements of the clinical description 
have led to profound errors in the interpretation of the data, such as the lack of stratification of patients according to severity, which is also an error related to people who no longer practice or have never practiced medicine, and who make a single entity of a disease that has different stages, different degrees of severity, and different potential risks of mortality.

In this context, conflicting studies on HCQ and remdesivir provide an opportunity to identify intrinsic criteria of studies associated with their qualitative results (treatment is deleterious or beneficial). Indeed, quantitative meta-analysis is not appropriate when direction of effect is not consistent among studies, as is the case for HCQ and remdesivir. Such qualitative meta-synthesis may help identify qualitative criteria not included in the current guidelines or checklists to improve future research in COVID-19 and beyond.

\section{Material and methods:}

\section{Inclusions of studies: Search strategy}

The global strategy to identify new evaluation criteria is detailed in Supplementary Data. Briefly, the keywords "hydroxychloroquine", "HCQ", "chloroquine", "coronavirus", "COVID-19", "SARS-CoV-2", and "remdesivir" were entered into PubMed, MedRxiv, Google Scholar and Google search engines on studies published in English Language from March to November 11, 2020. Only the death outcome was considered, so studies without any death were not eligible. We reviewed studies evaluating the effects of chloroquine derivatives and remdesivir against SARS-CoV2 in groups of COVID-19 patients as compared to control groups of patients who did not receive any experimental treatment.

\section{Identification of characteristics and criteria}

The criteria are summarized in Table 1 and detailed in the Supplementary Data. Some of these criteria have already been identified in previous works $(14,15)$ and have been completed, as we observed critical pitfalls in studies assessed for the present work.

\section{Multiple Correspondence Analysis}

The Multiple Correspondence Analysis (MCA) is a statistically based visualization method that allows the user to graphically represent and analyze the associations among categorical variables (16). The basic idea behind our approach was; (i) to use MCA to construct synthetic quantitative variables that represent the studies, their characteristics, and their criteria (Table 1) on a two-dimensional plane, and (ii) to identify clusters of studies that shared the same criteria and characteristics. MCA was performed with the $\mathrm{R}$ software and the FactoMineR package (17).

Table 1: Twenty quality criteria proposed to assess future clinical therapeutic studies in infectious diseases

\begin{tabular}{|c|c|c|}
\hline & Proposed quality criteria & Conflict of interest \\
\hline 1. & Potential conflict of interest & $\begin{array}{l}\text { - } \quad \text { Work funded by a company with a conflict of interest } \\
\text { At least one author compensated by a company with a conflict of interest } \\
\text { (received fee) declared by this author, or not declared (identified through } \\
\text { transparency websites and/or internet investigations) } \\
\text { A private data computing company (see definition below) }\end{array}$ \\
\hline 2. & Private data computing company & $\begin{array}{l}\text { A for-profit company collecting, aggregating, and computing } \\
\text { data in "Big Data" studies (with frequent unclear funding) }\end{array}$ \\
\hline 3. & $\begin{array}{l}\text { Undeclared funding and conflict of } \\
\text { interest }\end{array}$ & $\begin{array}{l}\text { - } \quad \text { Funding of the work not mentioned. } \\
\text { A conflict of interest not declared by an author but found through } \\
\text { transparency websites (dollarfordocs, eurosfordocs) or other means } \\
\text { (through internet investigations). } \\
\text { An indirect funding through a shell company by a company with a } \\
\text { conflict of interest }\end{array}$ \\
\hline
\end{tabular}

\begin{tabular}{lll}
\hline Known centers and doctors & Centers and doctors' identification \\
\hline Patients without confirmation of diagnosis $\bullet$ & $\begin{array}{l}\text { Recruiting centers and investigating doctors who directly take } \\
\text { care of patients in the clinical unit (at least one by center) are } \\
\text { identified }\end{array}$ \\
\hline by a microbiological test are excluded & $\begin{array}{l}\text { A patient is considered infected only if the infection is confirmed in the } \\
\text { laboratory (PCR, blood culture, serology). Clinical or CT-scan definition } \\
\text { not sufficient }\end{array}$ \\
\hline Detailed standard of care (SoC) & $\begin{array}{l}\text { The standard care of patients with or without experimental treatment is } \\
\text { reported (including criteria for admission, vital monitoring, initial } \\
\text { check-up, anticoagulants, oxygenotherapy...). This standard care is likely }\end{array}$
\end{tabular}




\begin{tabular}{lll}
\hline Detailed therapeutic protocol & $\begin{array}{l}\text { to influence outcome in a greater extent than the experimental treatment } \\
\text { itself. } \\
\text { Change over time of standard of care should be reported }\end{array}$ \\
\hline $8 . \quad$ Treatment not toxic & - & $\begin{array}{l}\text { With at least most frequent contraindications assessed, dosage, and } \\
\text { duration }\end{array}$ \\
\hline $9 . \quad$ Treatment monitoring & $\begin{array}{l}\text { Dosage is usual (not overdosed) and known to be well tolerated, } \\
\text { treatment is effectively not used in patients with contra-indications }\end{array}$ \\
\hline $\begin{array}{ll}\text { Side effects are reported } \\
\text { Critical (serious) side effects are reported (death, organ failure). If any } \\
\text { death were related to experimental treatment, it should be mentioned } \\
\text { Interruption of experimental treatment because of side effect }\end{array}$
\end{tabular}

\begin{tabular}{ll}
\hline 10. & Untreated group is not treated \\
\hline $11 . \quad \begin{array}{l}\text { At least one main author is a clinical } \\
\text { expert-in-the-field }\end{array}$
\end{tabular}

12. Confounding role of previous health status (at least age) is ruled out
Group without experimental treatment does not receive another specific treatment

At least one author directly takes care of patients and is specialized in this care (for a respiratory viral disease, this includes an infectious disease specialist, an internal medicine specialist or a pneumologist)

Confounding role of severity (at least
vital parameters) is ruled out

Previous health status should be assessed (at least age) and controlled for. This could be achieved using comorbidity score (Combined Charlson score). Previous health status should not be different at baseline and/or approaches should be used to control it (matching, multivariate analyses). Authors should provide evidence that this confounding has been controlled (for instance, age and comorbidities after matching are shown and not different)

Initial severity should be assessed (at least vital parameters) and controlled for. This could be achieved using severity score (NEWS score). Initial severity should not be different at baseline and/or approaches should be used to control it (matching, multivariate analyses). Authors should provide evidence that this confounding has been controlled (for instance, initial severity after matching is shown and not different)

\begin{tabular}{lll}
\hline $14 . \quad \begin{array}{l}\text { Different stages of the disease are not } \\
\text { mixed }\end{array}$ & $\begin{array}{l}\text { Different treatment could be associated with different effect at } \\
\text { different stages of the disease. Results should be stratified by } \\
\text { stage of the disease (for instance outpatient, non-severe or } \\
\text { severe inpatient or early versus late) according to previous knowledge of } \\
\text { the disease }\end{array}$
\end{tabular}

\begin{tabular}{lll}
\hline $\begin{array}{l}\text { Identification of observational and } \\
\text { interventional studies }\end{array}$ & Methodology \\
\hline 15. & $\begin{array}{l}\text { Observational studies may be a case/control (dead/alive) or } \\
\text { exposed/unexposed (treated/untreated). In this case, covariables are } \\
\text { adjusted by matching, propensity score approaches or multivariate } \\
\text { analysis. } \\
\text { Interventional studies may be randomized studies, and theoretically the } \\
\text { patient's situation is comparable }\end{array}$
\end{tabular}

15.1. Among observational studies, identification of electronic ("Big Data") versus clinical studies
Studies should be classified as 'electronic' or 'big data' studies when conducted on electronic medical records extracted by public-health specialists and epidemiologists who did not care for COVID-19 patients themselves.

- $\quad$ Conversely, studies should be classified as 'clinical studies' when the authors are physicians who cared for COVID-19 patients themselves

\begin{tabular}{lll}
\hline 15.2. & $\begin{array}{l}\text { Among interventional studies, } \\
\text { identification of megatrials }\end{array}$ & Large-scale interventional trials including several centers (usually > 10) \\
\hline 16. & $\begin{array}{l}\text { Identification of monocentric and } \\
\text { multicentric studies, and center effect is } \\
\text { evaluated in multicentric studies }\end{array}$ & $\begin{array}{l}\text { Multicentric observational (including "Big Data" studies) and } \\
\text { interventional (including megatrials) studies are sensitive to } \\
\text { Simpson's paradox effect. Therefore, in multicentric studies, } \\
\text { adjusted results should be reported for each center, using forest } \\
\text { plot. } \\
\end{array}$ \\
& $\bullet \quad \begin{array}{l}\text { Summary effect calculation should use random effects models } \\
\text { since experimental conditions are inevitably different among } \\
\text { different centers recruiting human patients. Indeed, in contrast to } \\
\text { mouse lines in environmentally controlled cages (where fixed effect model } \\
\text { could be used), standard of care and human populations are always } \\
\text { genetically, environmentally, and behaviorally different between centers. }\end{array}$
\end{tabular}




\begin{tabular}{lll}
\hline 17. & Objective is objective and invariant & $\bullet$
\end{tabular}$\quad \begin{aligned} & \text { The main outcome is objective, independent of human subjectivity and } \\
& \text { context (death, viral load) and should not change during study }\end{aligned}$

\begin{tabular}{lll}
\hline $18 . \quad \begin{array}{l}\text { Number of events and total sample size } \\
\text { mentioned for each group in each center }\end{array}$ & This may improve verifiability \\
\hline $19 . \quad \begin{array}{l}\text { Conclusions do not neglect a } 25 \% \\
\text { difference in risk of death (in whole } \\
\text { population or any subgroup) }\end{array}$ & $\begin{array}{l}\text { An observation of a relevant change in mortality risk in the whole } \\
\text { population or in any secondary analysis (subgroup, etc...) should be } \\
\text { reported and discussed, regardless of significance. In this case, the } \\
\text { authors should calculate the number of participants that would be needed } \\
\text { to significantly confirm the effect observed in the relevant group and, if } \\
\text { data from similar studies are available, conduct a meta-analysis to } \\
\text { eliminate a lack of statistical power }\end{array}$
\end{tabular}

\begin{tabular}{lll}
\hline $20 . \quad$ Clinical relevance should be evaluated & $\begin{array}{l}\text { When a difference is observed regardless of significance, the number } \\
\text { needed to treat (NNT) to prevent an event in the specified risk group should } \\
\text { be reported. Assessment of clinical relevance may also include the years of } \\
\text { life lost (YLL), years lived with disability (YLD) and disability adjusted life } \\
\text { years (DALY) }\end{array}$ \\
\hline $21 . \quad$ Unexpected findings may be reported & $\begin{array}{l}\text { When a non-prespecified effect is observed and clinically relevant, it } \\
\text { should be analyzed. For instance, a clinically relevant effect in a specific } \\
\text { subgroup }\end{array}$
\end{tabular}

\begin{tabular}{ll}
\hline & Data sharing \\
\hline $\begin{array}{l}\text { Additional criterion: Data should be shared within } \bullet \\
12 \text { months }\end{array}$ & Data sharing may improve verifiability \\
\hline
\end{tabular}

\section{Predictive value}

In a qualitative meta-synthesis approach, we evaluated the predictive value of the presence or absence of the identified criterion on the positive (Odds Ratio for mortality $<1$; identified as Pro regardless of significance) or negative ( $O R \geq 1$; identified as Con) outcome of the included studies. The association of the presence or absence of each criterion with Pro or Con was tested using a two-sided Fisher exact test. A p-value $<0.05$ was considered significant.

\section{Meta-analysis and heterogeneity}

To confirm the qualitative approach, when applicable, a comparative meta-analysis was performed with a random effects model using Comprehensive Meta-Analysis (CMA, RRID: SCR_012779) v3 (Biostat, Englewood, NJ, USA) as recommended by Borenstein et al., (18). The most adjusted effect size, reflecting the greatest control for potential confounding factors, was extracted. When propensity score matching was used, the number of matched patients was included in quantitative analysis. Heterogeneity was considered substantial when $\mathrm{I}^{2}>50 \%$. A p-value $<0.05$ was considered significant. To identify which criteria were associated with a significant difference in summary effect, the Q-value and its $\mathrm{p}$-value were reported, and criteria were ranked according to Q-value.

\section{Validation of predictive criteria}

The most predictive criteria were validated on an independent data set of 10 addi- tional studies (validation set) not included in the group of studies used for criteria identification (training set). The performance of the selected criteria was assessed by comparing the direction of effects of each additional study with the direction of the effect of the majority $(>50 \%)$ of studies with identical criteria in the training set.

\section{Results:}

\section{Multiple Correspondence Analysis}

Unsupervised analysis (Fig 1) of $\mathrm{HCQ}$ studies evidenced three clusters. First, megatrials and RCTs were associated with most prestigious medical journals with highest impact factor, unclear affiliations of authors, absence of laboratory confirmation of diagnosis, toxic treatment (overdose or use in contraindicated patients), unexpected results not reported and conclusions neglecting a $25 \%$ decrease in the risk of mortality.

A second cluster regrouped Big Data studies that were associated with private data computing company of unknown financing (and therefore a likely existence of a conflict of interest), a potential conflict of interest, unknown centers and doctors, undeclared funding and conflict of interests, and absence of detailed therapeutic protocol and treatment monitoring. These studies were also associated with the absence of an expert in the field among the authors and a role of previous health status and severity not ruled out (confounding by indication). 


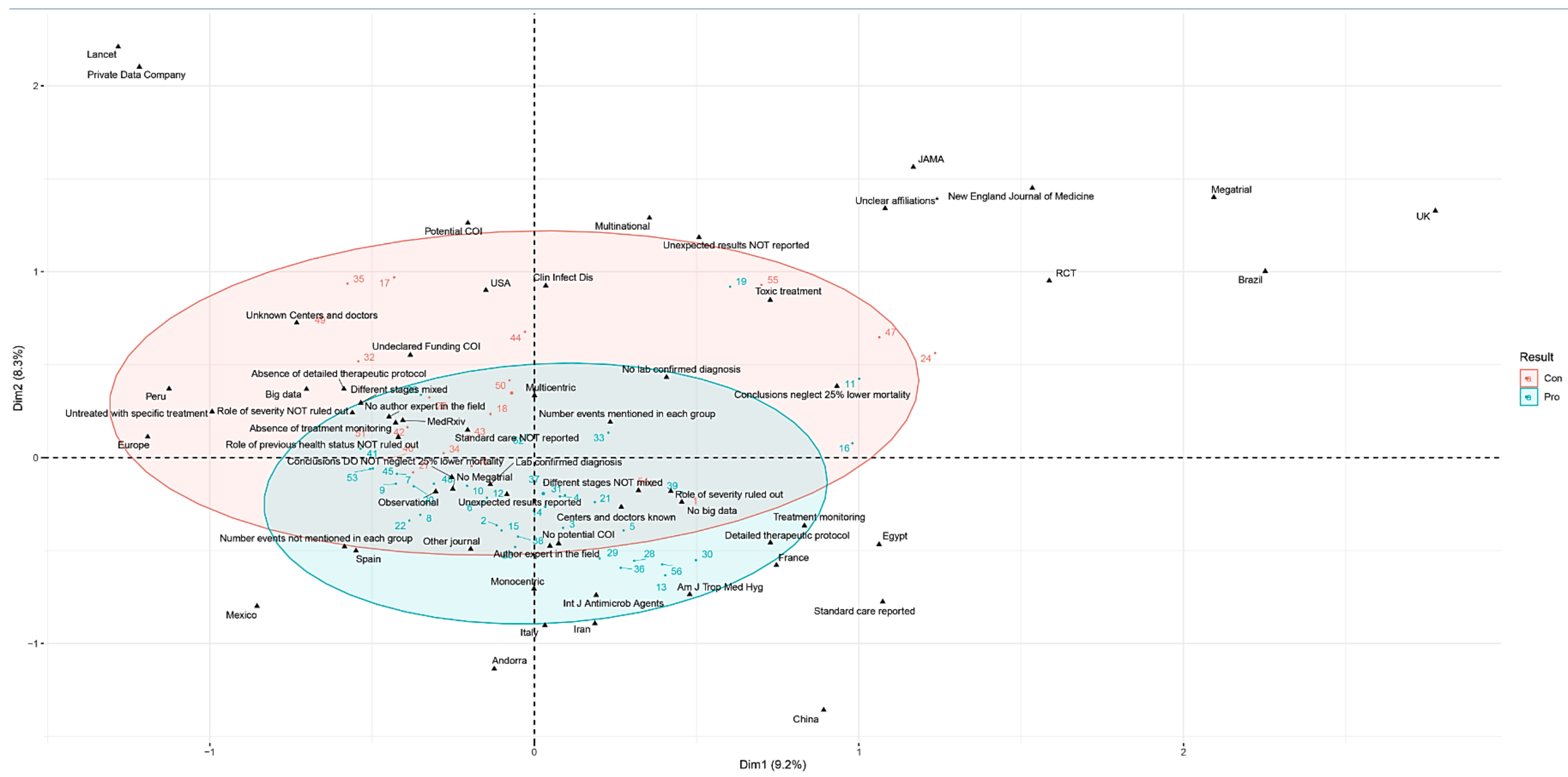

Fig 1: Multiple Correspondence Analysis (MCA) including all the characteristics of studies $(n=56)$

Unsupervised approaches (such as MCA for qualitative variables) allow graphical representation without a priori that takes together the variables and observations (biplot). Studies and their characteristics can be identified and analyzed according to an additional variable (such as direction of effect of studies Pro/Con). Direction of effect of each study is indicated in green (Pro) and red (Con). Ellipses cluster $90 \%$ of the points belonging to the two groups chosen. *Unclear affiliations: For these studies, it could not be easily determined whether at least one main author is a clinical expert-in-the-field who directly take care of COVID-19 patients (see Table 1 ) 
Conversely, monocentric studies were associated with absence of potential conflict of interest, an author expert in the field, a detailed therapeutic protocol, a detailed treatment monitoring, and standard care reported. This cluster was associated with Andorra, China, Egypt, France, Iran, Italy, Mexico, and Spain. These studies were mainly observational (but not "Big Data" studies), with a laboratory confirmation of the diagnosis, the different stages of disease kept separate, role of severity ruled out, centers and doctors clearly reported with at least one author expert in the field. These studies were associated with 2 journals; American Journal of Tropical Medicine and Hygiene, and International Journal of Antimicrobial Agents.

\section{Predictive value}

Among the 6 studies on the broadspectrum antiviral drug candidate recently dev eloped by a biopharmaceutical company, both positive and negative predictive values of potential conflict of interest with remdesivir were $100 \%$. All 5 studies with a conflict of interest declared or not declared were in favor of remdesivir, the only study without conflict of interest reported no benefit with remdesivir. Among the 56 studies on HCQ, the following criteria were associated with a predictive value $>50 \%$ for HCQ efficacy (Table 2 ); detailed treatment protocol $(84 \%)$, at least one of the main authors expert in the field (affiliated in infectious diseases, internal medicine or pneumology) (76\%), control for severity (at least oxygen) (75\%), centers and doctors who took care of patients are identified $(73 \%)$, diagnosis formally confirmed (PCR or serology-based diagnosis) (69\%) and control for health status (at least age) (63\%).

Conversely, the following criteria were associated with a predictive value significantly

Table 2: Predictive value of each criterion for the issue of clinical assays for HCQ

\begin{tabular}{|c|c|c|c|}
\hline \multirow[b]{2}{*}{ Proposed criteria } & Con HCQ & Pro HCQ & \multirow{2}{*}{ p-value* } \\
\hline & n (\%) & n (\%) & \\
\hline $\begin{array}{l}\text { Potential conflict of interest }(n=15) \\
\text { No potential conflict of interest }(n=41)\end{array}$ & $\begin{array}{l}11(73.3) \\
9(21.9)\end{array}$ & $\begin{array}{l}4(26.7) \\
32(78.1)\end{array}$ & 0.001 \\
\hline $\begin{array}{l}\text { Detailed therapeutic protocol }(n=25) \\
\text { Absence of detailed therapeutic protocol }(n=31)\end{array}$ & $\begin{array}{l}4(16.0) \\
16(51.6)\end{array}$ & $\begin{array}{l}21(84.0) \\
15(48.4)\end{array}$ & 0.011 \\
\hline $\begin{array}{c}\text { Toxic treatment }(n=4) \\
\text { Non-toxic treatment }(n=52)\end{array}$ & $\begin{array}{l}4(100.0) \\
16(30.8)\end{array}$ & $\begin{array}{c}0 \\
36(69.2)\end{array}$ & 0.013 \\
\hline $\begin{array}{l}\text { Known centers and doctors }(n=41) \\
\text { Unknown centers and doctors }(n=15)\end{array}$ & $\begin{array}{l}11(26.8) \\
9(60.0)\end{array}$ & $\begin{array}{l}30(73.2) \\
6(40.0)\end{array}$ & 0.030 \\
\hline $\begin{array}{l}\text { Private data computing company }(n=3) \\
\text { No private data computing company }(n=53)\end{array}$ & $\begin{array}{l}3(100.0) \\
17(32.1)\end{array}$ & $\begin{array}{c}0(0.0) \\
36(67.9)\end{array}$ & 0.041 \\
\hline $\begin{array}{l}\text { Declared Funding COI }(n=47) \\
\text { Undeclared funding COI }(n=9)\end{array}$ & $\begin{array}{l}14(29.8) \\
6(66.7)\end{array}$ & $\begin{array}{l}33(70.2) \\
3(33.3)\end{array}$ & 0.056 \\
\hline $\begin{array}{c}\text { Observational }(n=47) \\
\text { Not observational }(n=9)\end{array}$ & $\begin{array}{l}14(29.8) \\
6(66.7)\end{array}$ & $\begin{array}{l}33(70.2) \\
3(33.3)\end{array}$ & 0.056 \\
\hline $\begin{array}{c}\text { Role of severity ruled out }(n=32) \\
\text { Role of severity not ruled out }(n=24)\end{array}$ & $\begin{array}{c}8(25.0) \\
12(50.0)\end{array}$ & $\begin{array}{l}24(75.0) \\
12(50.0) \\
\end{array}$ & 0.090 \\
\hline $\begin{array}{c}\text { Big data }(\mathrm{n}=22)^{* *} \\
\text { No big data }(\mathrm{n}=34) \\
\end{array}$ & $\begin{array}{l}11(50.0)^{* *} \\
9(26.5)\end{array}$ & $\begin{array}{c}11(50.0)^{* *} \\
25(73.5) \\
\end{array}$ & 0.092 \\
\hline $\begin{array}{l}\text { Number of events and total mentioned for each group }(n=40) \\
\text { Number of events and total not mentioned for each group }(n=16)\end{array}$ & $\begin{array}{l}17(42.5) \\
3(18.8)\end{array}$ & $\begin{array}{l}23(57.5) \\
13(81.3)\end{array}$ & 0.13 \\
\hline $\begin{array}{c}\text { Standard care reported }(n=9) \\
\text { Standard care not reported }(n=47)\end{array}$ & $\begin{array}{c}1(11.1) \\
19(40.4)\end{array}$ & $\begin{array}{l}8(88.9) \\
28(59.6)\end{array}$ & 0.136 \\
\hline $\begin{array}{c}\text { Treatment monitoring }(n=19) \\
\text { Absence of treatment monitoring }(n=37)\end{array}$ & $\begin{array}{c}4(21.1) \\
16(43.2)\end{array}$ & $\begin{array}{l}15(78.9) \\
21(56.8)\end{array}$ & 0.143 \\
\hline $\begin{array}{l}\text { Lab confirmed diagnosis }(n=42) \\
\text { No lab confirmed diagnosis }(n=14)\end{array}$ & $\begin{array}{l}13(30.9) \\
7(50.0) \\
\end{array}$ & $\begin{array}{l}29(69.1) \\
7(50.0) \\
\end{array}$ & 0.198 \\
\hline $\begin{array}{l}\text { Monocentric }(\mathrm{n}=18) \\
\text { Multicentric }(\mathrm{n}=38) \\
\end{array}$ & $\begin{array}{c}4(22.2) \\
16(42.1)\end{array}$ & $\begin{array}{l}14(77.8) \\
22(57.9)\end{array}$ & 0.2326 \\
\hline $\begin{array}{l}\text { One author expert in the field }(n=29) \\
\text { No author expert in the field }(n=20)\end{array}$ & $\begin{array}{l}7(24.1) \\
8(40.0)\end{array}$ & $\begin{array}{l}22(75.9) \\
12(60.0)\end{array}$ & 0.345 \\
\hline $\begin{array}{c}\text { Different stages mixed }(n=21) \\
\text { Different stages not mixed }(n=35)\end{array}$ & $\begin{array}{c}9(42.9) \\
11(31.4)\end{array}$ & $\begin{array}{l}12(57.1) \\
24(68.6)\end{array}$ & 0.405 \\
\hline $\begin{array}{c}\text { Unexpected results reported }(n=48) \\
\text { Unexpected results not reported }(n=8)\end{array}$ & $\begin{array}{l}16(33.3) \\
4(50.0)\end{array}$ & $\begin{array}{l}32(66.7) \\
4(50.0)\end{array}$ & 0.437 \\
\hline $\begin{array}{l}\text { Conclusions neglect a } 25 \% \text { decrease in mortality }(n=12) \\
\text { Conclusions do not neglect a } 25 \% \text { decrease in mortality }(n=44)\end{array}$ & $\begin{array}{c}3(25.0) \\
17(38.6)\end{array}$ & $\begin{array}{c}9(75.0) \\
27(61.4)\end{array}$ & 0.506 \\
\hline $\begin{array}{c}\text { Megatrial }(n=6) * * \\
\text { Not a megatrial }(n=50)\end{array}$ & $\begin{array}{c}3(50.0)^{* *} \\
17(34.0)\end{array}$ & $\begin{array}{l}3(50.0)^{* *} \\
33(66.0)\end{array}$ & 0.6553 \\
\hline $\begin{array}{l}\text { Role of previous health status ruled out }(n=45) \\
\text { Role of previous health status not ruled out }(n=11)\end{array}$ & $\begin{array}{l}17(37.8) \\
3(27.3)\end{array}$ & $\begin{array}{l}28(62.2) \\
8(72.7)\end{array}$ & 0.728 \\
\hline $\begin{array}{c}\text { Untreated group with specific treatment }(n=2) \\
\text { Untreated group without specific treatment }(n=54)\end{array}$ & $\begin{array}{l}1(50.0) \\
19(35.2)\end{array}$ & $\begin{array}{c}1(50.0) \\
35(64.8)\end{array}$ & 1.000 \\
\hline $\begin{array}{l}\text { Death as a clear outcome }(n=47) \\
\text { Death not a clear outcome }(n=9)\end{array}$ & $\begin{array}{c}17(36.2) \\
3(33.3)\end{array}$ & $\begin{array}{c}30(63.8) \\
6(66.7)\end{array}$ & 1.000 \\
\hline
\end{tabular}


Table 3. Observational studies with a detailed therapeutic protocol without potential conflict of interest

\begin{tabular}{ccc} 
Study name & $\begin{array}{c}\text { Inpatients/ } \\
\text { Outpatients/ } \\
\text { Both }\end{array}$ & Country \\
\hline Alberici, Kidney International, 2020 & Both & Italy \\
Arshad, Int J Infect Dis, 2020 & Inpatients & PSA \\
Ashraf, MedRxiv, 2020 & Inpatients & Iran \\
Ayerbe, Intern Med Emerg, 2020 & Inpatients & Spain \\
Patteau, Int J Antimicrob Agents, 2020 & Inpatients & Belgique \\
Davido, Int J Antimicrob Agents, 2020 & France \\
Derwand, Int J Antimicrob Agents, 2020 & USA \\
Di Castelnuovo, Eur J Intern Med, 2020 & Outpatients & Pro \\
Guerin, Asian J Med Health, 2020 & Inpatients & Pro \\
Lagier, Trav Med Infect Dis, 2020 & Outpatients & Prance \\
Lauriola, Clinical Transl Sci, 2020 & Both & France \\
Lecronier, Critical Care, 2020 & Inpatients & Italy \\
Membrillo de Novales, Preprints, 2020 & ICU & France \\
Mikami, J Gen Intern Med, 2020 & Spain \\
Nachega, Am J Trop Med Hyg, 2020 & Inpatients & USA \\
Paccoud, Clin Infect Dis, 2020 & Inpatients & Congo \\
Sulaiman, MedRxiv, 2020 & Inpatients & Pro \\
Yu, Sci Chi Life Sci, 2020 & Inpatients & Pro \\
\hline
\end{tabular}

All these 18 studies were in favor of a HCQ efficacy (100\% predictive value). ICU: Intensive care unit

greater than $50 \%$ for HCQ inefficacy; private data computing company $(100 \%)$, toxic treatment $(100 \%)$, potential conflict of interest with remdesivir $(73 \%)$, and undeclared funding or conflict of interest $(66 \%)$. The difference of predictive value according to each criterion was significant for potential conflict of interest $(p=0.001)$, lack of detailed therapeutic protocol $(p=0.011)$, toxic treatment $(p=0.013)$, unknown centers and doctors not known $(p=0.03)$, and private data computing company $(p=0.041)$.

The 18 observational studies with a detailed therapeutic protocol and without a potential conflict of interest had a $100 \%$ predictive value for HCQ efficacy (Table 3). Considering the odds ratio, apart from toxic treatment and private data computing companies (perfect predictors), conflict of interest was the strongest predictor of HCQ inefficiency $(\mathrm{OR}=9.8,95 \% \mathrm{CI}=2.50-38.2$, Fig 2$)$.

\section{Comparative meta-analysis}

Among these 18 studies, 17 provided quantitative results available for meta-analysis with a significant beneficial effect $(n=17$, $\mathrm{OR}=0.60,95 \% \mathrm{CI}=0.52-0.70, \mathrm{p}=6.7 \times 10^{-12}$ ). This was not related to an isolated aberrant study as shown by one-study-removed metaanalysis (Supplementary Fig 1). Combination of HCQ with azithromycin (AZ) was associated with a significant beneficial effect compared to HCQ monotherapy $(n=5$ comparisons with HCQ-AZ in all patients, $0.36,0.21-0.63 / n=9$ with $\mathrm{HCQ}$ but not $A Z$ in any patient, 0.68 , 0.56-0.82/Q-value $=4.41, p=0.036$ ) .

Comparative meta-analysis with ranking by $\mathrm{Q}$-value confirmed that potential conflict of interest, including private data computing company, was the criterion associated with the greatest and most significant difference in summary effect (Supplementary Table 1). Effect of HCQ on mortality was beneficial $\left(n=43,0.75,0.66-0.84, p=6.3 \times 10^{-7}\right)$ or deleterious $\left(n=19,1.15,1.07-1.23, p=1.1 \times 10^{-4}\right)$ when an absence or a presence of a potential conflict of interest was found, respectively (Fig 3).

Neglecting a non-significant but relevant dec-
rease in mortality rease in the risk of mortality greater than $25 \%$ but this finding was not analyzed nor mentioned because; (i) it was not significant (underpowered studies) or (ii) thought not to be relevant to the outcome of the study (Supplementary Data). We have already commented on these two frequent issues (19). Strikingly, the day-28 mortality was halved in a French RCT (20) suspended and closed after the publication of Mehra et al., (2). The difference was clinically relevant since the number of patients needed to prevent 1 death was 25 (mortality at day 28 of $4.8 \%$ in HCQ and $8.9 \%$ in untreated). If the planned enrollment had been included (1300 patients), if the observed tendance were confirmed, the difference would have been significant [(31/650 (4.8\%) versus $58 / 650(8.9 \%)$, OR 0.55 , two-sided Mid-p exact test $p=0.003)$ ].

\section{Validation of predictive criteria}

Finally, we validated the identified criteria by analysing 10 additional studies not included in the first analysis. All 10 studies were correctly classified as favorable or unfavorable based on the most significant criteria (Supplementary Table 3). All the 3 Con studies were associated with potential conflict of interest and were from the same country (USA), while the other 7 Pro studies were from Brazil, China, France, Mexico and Spain. This was consistent with MCA (Fig 1). In agreement with predictive value analysis and comparative meta-analysis (Figs $2 \& 3$ ), potential conflict of interest was a perfect predictor in this validation data set. 


\section{Criterium}

Toxic treatment (4/4 Con)

Private data computing company ( $3 / 3$ Con)

Potential conflict of interest

Absence of detailed therapeutic protocol

Standard care not reported

Undeclared Funding or $\mathrm{COI}$

Not observational

Unknown centers and doctors

Role of severity not ruled out

Absence of treatment monitoring

Big data

Multicentric study

Absence of laboratory confirmation

No author expert in the field

Unexpected results not reported

Megatrial

Untreated group with specific treatment

Different stages mixed

Death not as a clear outcome

Role of previous health status not ruled out

Conclusions neglect a $25 \%$ decrease in mortality

Number of events and total not mentioned for each group

\begin{tabular}{|ccc}
\hline Odds ratio & Odds ratio & p-value \\
Perfect predictor & $\infty$ & 0.013 \\
Perfect predictor & $\infty$ & 0.041 \\
\hline & 9.78 & 0.001 \\
\hline & 5.60 & 0.011 \\
\hline & 5.43 & 0.14 \\
\hline & 4.71 & 0.056 \\
\hline & 4.71 & 0.056 \\
\hline & 4.09 & 0.03 \\
\hline & 3.00 & 0.09 \\
\hline & 2.86 & 0.14 \\
\hline & 2.78 & 0.09 \\
\hline & 2.55 & 0.23 \\
\hline & 2.23 & 0.20 \\
\hline & 2.10 & 0.34 \\
\hline & 2.00 & 0.44 \\
\hline & 1.94 & 0.65 \\
& 1.84 & 1 \\
\hline & 1.64 & 0.40 \\
\hline & 0.88 & 1 \\
\hline & 0.62 & 0.73 \\
& 0.53 & 0.51 \\
& 0.31 & 0.13 \\
\hline
\end{tabular}

Fig 2: Predictive factors of clinical assays during COVID-19 


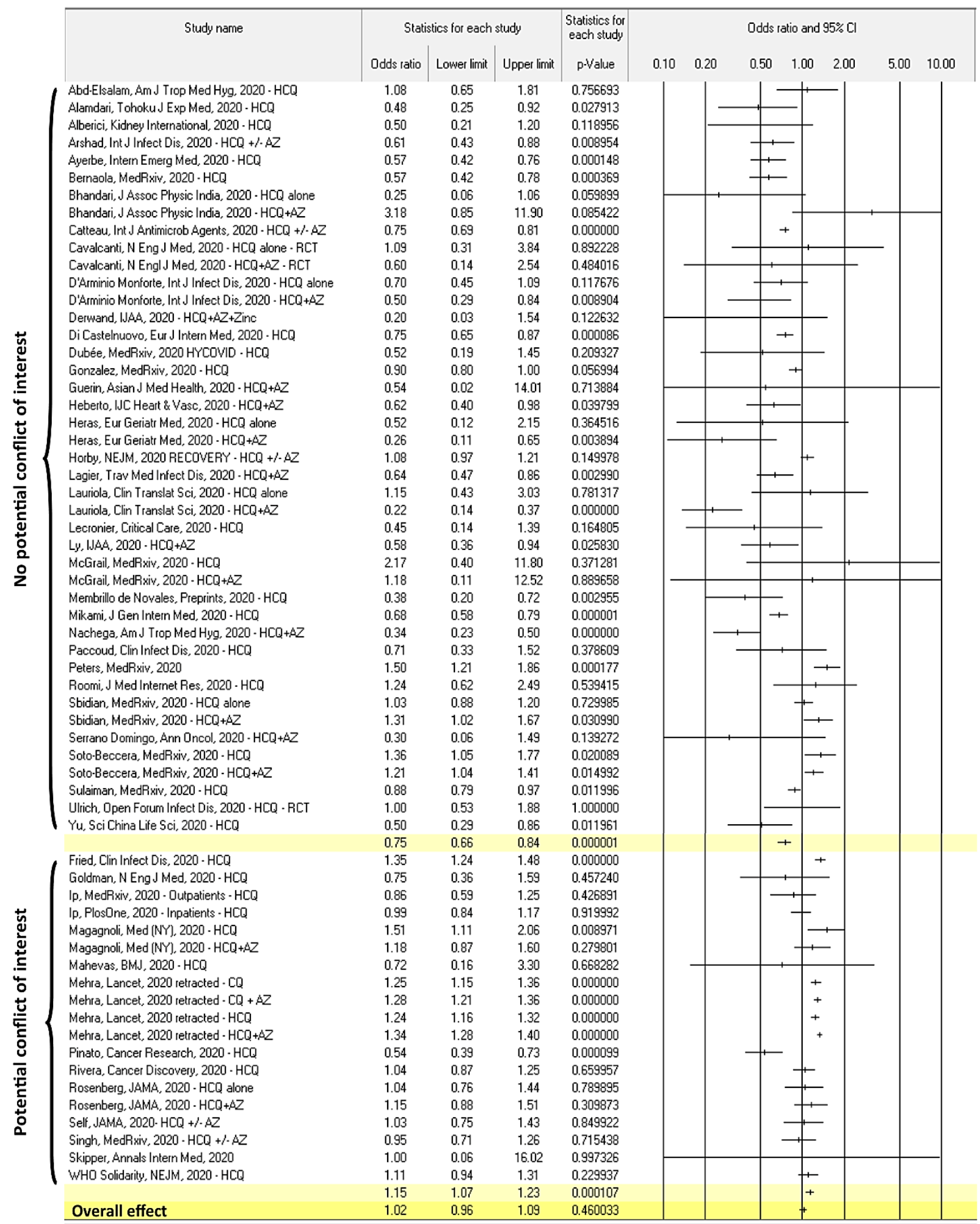

Fig 3: HCQ meta-analysis according to potential conflict of interest

95\% CI: 95\% confidence interval. Random effects model

\section{Discussion:}

There is a conflict in the evaluation of therapeutics for infectious diseases between several public health specialists and methodologists who recommend multicentric randomized controlled trials (RCTs), which are mainly used by the pharmaceutical industry, and observational studies performed by medical doctors. More recently, a third source of comparative analysis has been the analysis of large data (Big Data) collected automatically in health care centers. Interestingly in infectious diseases currently, $83 \%$ of IDSA recommendations are not based on RCTs (21), although considered the "gold standard". More- 
over, RCTs require significant funding, and the pharmaceutical industry's willingness to demonstrate efficacy or non-inferiority is under pressure of conflict of interest because those who pay and analyze have a well-known and long-evaluated chance of having biased results in favor of the products they finance (8). In addition, the company's provision of the compound to be tested is usually subject to possible censorship, as approval of the submitted work is required (22). That may lead to dissimulate negative results (22).

The methodology of analysis used here is to our knowledge unique. Pharmaceutical industry is a major actor directly or indirectly influencing authors with conflicts of interest, declared or not. Potential conflict of interest has a predictive value of $74 \%$ against $\mathrm{HCQ}$ in the training set (whereas $78 \%$ of the studies with no link to this company was in favor of HCQ) and $100 \%$ in the validation set. This work also made it possible to identify the target journals of the studies in which the remdesivir producer or its partners played an important role.

Concerning Big Data, this is a new problem. In some Big Data studies, data acquisition is directly financed by the pharmaceutical industry with a conflict of interest against HCQ $(23,24)$. In another Big Data study reporting a beneficial effect of remdesivir and a deleterious effect of $\mathrm{HCQ}$, a direct conflict of interest was declared by several authors (25). Companies such as Surgisphere, two papers of which had to be retracted $(2,3)$, have unknown funding, something that should have been required from the publisher. One may question if data companies $(2,24,26)$ have received funding since these "Big Data" studies also clearly have a predictive value in favor of remdesivir (24) and to the disadvantage of $\operatorname{HCQ}(2,24,26)$. This suggests that potential conflict of interest must be sought well beyond the mere declaration of conflict of interest by authors or direct funding of studies. Conversely, individual monocentric studies focusing on HCQ have multiplied and are associated with the success of HCQ.

These three elements (potential conflict of interest, private data computing company, and multi- or mono-centric studies) can predict the outcome of the meta-analysis based on the choices that will be made to retain certain studies. Number of studies were conducted ignoring the very basis of inclusions at the medical level i. e. clinical signs found in this disease (not yet reported in acute respiratory infection in general) such as anosmia and ageusia, and pulmonary embolisms, are not in the clinical diagnostic criteria. On the other hand, some studies have been published without even confirmatory biological tests (27, 28), which for infectious diseases is a regression that has no equivalent. Finally, in most cases the evaluation of treatments in the different stages of the disease should correspond to different therapeutic options, and this is often not evaluated.

All in all, this crisis highlighted very different therapeutic evaluation strategies. The considerable weight of the pharmaceutical industry on the results of therapeutic trials is clear $(1,5,8,29,30)$. Meta-analyses allow small studies to be analyzed and multicenter studies should report results by center so that investigators can ensure validity, and to avoid the Simpson effect (31). A French megatrial (32), recruiting patients in 32 French sites, and an international megatrial recruiting patients in 405 hospitals in 30 countries (4) did not stratify by region of inclusion. Since the number of patients included per center (very low number of inclusions in some regions (32) and the effect for each center was not reported and may have been highly variable, both these megatrials are likely to be biased by the Simpson's effect.

Most of the criteria identified in this work (checklist detailed in Table 1) are new, are not part of the usual quality checklists (STROBE, CONSORT or PRISMA - see Supplementary Table 2) and may be useful for future critical review. This comeback to independent clinical and microbiological expertise is the best lesson to be learned from the global scandal we have witnessed, for the greatest benefit of patients.

\section{Author contributions:}

MM wrote the first draft of the manuscript (MS), revised the different versions of the MS, performed statistical analysis and analyzed all data, PD analyzed data, performed systematic research on the field and revised different versions of the MS, EC performed systematic research on the field, analyzed data and revised different versions of the MS, SC analyzed data, performed statistical analysis and revised different versions of the MS, YR performed systematic research on the field, analyze data, performed statistical analysis and revised the different versions of the MS, PB performed systematic research on the field, analyze data, performed statistical analysis and revised the different versions of the MS, and DR designed the work and revised the different versions of the MS.

\section{Funding:}

This work was funded by ANR-15CE36-0004-01 and by ANR "Investissements d'avenir", Méditerranée infection 10-IAHU-03, and was also supported by Région ProvenceAlpes-Côte d'Azur. This work had received financial support from the Mediterranean Infection Foundation. 


\section{Conflicts of interest:}

The authors declare that the research was conducted in the absence of any commercial or financial relationships that could be construed as a potential conflict of interest. Funding sources had no role in the design and conduct of the study; collection, management, analysis, and interpretation of the data; and preparation, review, or approval of the manuscript. Our group used widely available generic drugs distributed by many pharmaceutical companies.

\section{Supplemental Information}

Supplemental information can be accessed online at: www.afrjcem.org/supplementary materials

\section{References:}

1. Godlee, F. Covid-19: The lost lessons of Tamiflu. BMJ. 2020; 371: m4701. doi: https://doi.org/10.1136/bmj.m4701

2. Mehra, M. R., Desai, S. S., Ruschitzka, F., and Patel, A. N. RETRACTED: Hydroxychloroquine or chloroquine with or without a macrolide for treatment of COVID-19: a multinational registry analysis [published online ahead of print, 2020 May 22] [retracted in: Lancet. 2020 Jun 5: null]. Lancet. 2020a; S0140-6736 (20) 31180-6. doi:10.1016/S0140-6736(20)31180-6

3. Mehra, M. R., Desai, S. S., Kuy, S., Henry, T. D., and Patel, A. N. Cardiovascular disease, drug therapy, and mortality in Covid-19. N Engl J Med. 2020; 382: e102-e102

4. WHO Solidarity Trial Consortium., Pan, H., Peto, R., et al. Repurposed Antiviral Drugs for Covid-19 - Interim WHO Solidarity Trial Results [published online ahead of print, 2020 Dec 2]. N Engl J Med. 2020; doi:10.1056/NEJMoa2023184

5. Abbasi, K. Covid-19: politicisation, "corruption," and suppression of science. BMJ 2020; 371: $\mathrm{m} 4425$.

doi: https://doi.org/10.1136/bmj.m4425

6. Grein, J., Ohmagari, N., Shin, D., et al. Compassionate Use of Remdesivir for Patients with Severe Covid-19. N Engl J Med. 2020; 382 (24): 2327-2336. doi:10.1056/NEJMoa2007016

7. Lagier, J. C., Million, M., Gautret, P., et al. Outcomes of 3,737 COVID-19 patients treated with hydroxychloroquine/azithromycin and other regimens in Marseille, France: $A$ retrospective analysis. Travel Med Infect Dis. 2020; 36: 101791. doi:10.1016/j.tmaid.2020.101791

8. Bhandari, M., Busse, J. W., Jackowski, D., et al. Association between industry funding and statistically significant pro-industry findings in medical and surgical randomized trials. CMAJ. 2004; 170 (4): 477-80.

9. Roussel, Y., and Raoult, D. Influence of conflicts of interest on public positions in the COVID-19 era, the case of Gilead Sciences. New Microbes New Infect. 2020; 38: 100710

doi:10.1016/j.nmni.2020.100710

10. Fiolet, T., Guihur, A., Rebeaud, M. E., Mulot, M., Peiffer-Smadja, N., and Mahamat-Saleh, Y. Effect of hydroxychloroquine with or without azithromycin on the mortality of coronavirus disease 2019 (COVID-19) patients: a systematic review and me-ta-analysis [published online ahead of print, 2020 Aug 26]. Clin Microbiol Infect. 2020; S1198-743X(20)30505-X. doi:10.1016/j.cmi.2020.08.022
11.

Million $M$, Gautret $P$, Colson $P$, et al. Clinical efficacy of chloroquine derivatives in COVID-19 infection: comparative meta-analysis between the big data and the real world. New Microbes New Infect. 2020; 38: 100709. Published 2020a Jun 6. doi: $10.1016 /$ j.nmni.2020.100709

12. Concato, J., Shah, N., and Horwitz, R. I. Randomized, controlled trials, observational studies, and the hierarchy of research designs. $N$ Engl J Med. 2000; 342 (25): 1887-1892. doi:10.1056/NEJM200006223422507

13. Anglemyer, A., Horvath, H. T., and Bero, L. Healthcare outcomes assessed with observational study designs compared with those assessed in randomized trials. Cochrane Database Syst Rev. 2014;(4):MR000034. Published 2014 Apr 29. doi:10.1002/14651858.MR000034.pub2

14. Raoult, D. Lancet gate: a matter of fact or a matter of concern. New Microbes New Infect. 2020; 38: 100758 .

doi:10.1016/j.nmni.2020.100758

15. Raoult, D. Rational for meta-analysis and randomized treatment: the COVID-19 example [published online ahead of print, 2020 Oct 21]. Clin Microbiol Infect. 2020a; S1198-743X(20) 30643-1. doi:10.1016/j.cmi.2020.10.012

16. Greenacre, M. J., and Blasius, J. Multiple correspondence analysis and related methods. Chapman \& Hall/CRC, 2006.

17. Lê, S., Josse, J., and Husson, F. FactoMineR: An $\mathrm{R}$ Package for Multivariate Analysis. Journal of Statistical Software. 2008; 25 (1): 1-18.

18. Borenstein, M, Hedges, L. V., Higgins, J. P. T., and Rothstein, H. R. Introduction to Meta-Analysis. 2009. John Wiley \& Sons, Ltd. 2009

https://doi.org/10.1002/9780470743386

19. Million, M., Chaudet, H., and Raoult, D. Hydroxychloroquine Failure: The End does not justify the Means [published online ahead of print, 2020 Aug 6]. Clin Infect Dis. 2020c; ciaa1117. doi:10.1093/cid/ciaa1117

20. Dubée, V., Roy, P. M., Vielle, B., et al. for the HYCOVID study group A placebo-controlled double-blind trial of hydroxychloroquine in mild to - moderate COVID-19. medRxiv. 2020.10.19. 20214940

doi: https://doi.org/10.1101/2020.10.19.20214940

21. Khan, A. R., Khan, S., Zimmerman, V., Baddour, L. M., and Tleyjeh, I. M. Quality and strength of evidence of the Infectious Diseases Society of America clinical practice guidelines. Clin Infect Dis. 2010; 51 (10): 1147-1156 doi: $10.1086 / 656735$

22. Kasenda, B., von Elm, E., You, J. J., et al. Agreements between Industry and Academia on Publication Rights: A Retrospective Study of Protocols and Publications of Randomized Clinical Trials. PLoS Med. 2016; 13 (6): e1002046.

23. Roussel, Y., Million, M., Chabrière, E., Lagier, J. C., and Raoult, D. Be careful with Big Data: Reanalysis of Patient Characteristics and Outcomes of 11,721 Patients with COVID19 Hospitalized Across the United States [published online ahead of print, 2020 Oct 22]. Clin Infect Dis. 2020; ciaa1618. doi:10.1093/cid/ciaa1618

24. Fried, M. W., Crawford, J. M., Mospan, A. R., et al. Patient Characteristics and Outcomes of 11,721 Patients with COVID19 Hospitalized Across the United States [published online ahead of print, 2020 Aug 28]. Clin Infect Dis. 2020; ciaa1268. doi:10.1093/cid/ciaa1268

25. Flisiak, R., Zarębska-Michaluk, D., BerkanKawińska, A., et al. Remdesivir-based therapy improved recovery of patients with COVID-19 in the SARSTer multicentre, real-world study. medRxiv.2020.10.30.20215301;

doi: https://doi.org/10.1101/2020.10.30.20215301

26. Singh, S., Khan, A., Chowdhry, M., and Chatterjee, A. Outcomes of Hydroxychloroquine treatment among hospitalized COVID-19 patients in the United States - Real-World Evidence from a Federated Electronic Medical Record Network. 
medRxiv.2020.05.12;20099028:

doi:10.1101/2020.05.12.20099028

27. Boulware, D. R., Pullen, M. F., Bangdiwala, A. S., et al. A Randomized Trial of Hydroxychloroquine as Postexposure Prophylaxis for Covid-19. N Engl J Med. 2020;383(6):517-525

doi:10.1056/NEJMoa2016638

28. Skipper, C. P., Pastick, K. A., Engen, N. W., et al. Hydroxychloroquine in Non hospitalized Adults with Early COVID-19: A Randomized Trial [published online ahead of print, 2020 Jul 16]. Ann Intern Med. 2020. doi:10.7326/M20-4207

29. Sismondo, S. Epistemic Corruption, the Pharmaceutical Industry, and the Body of Medical
Science. Front Res Metr Anal. 2021; 6: 614013. doi: $10.3389 /$ frma.2021.614013

30. Lundh, A., Lexchin, J., Mintzes, B., Schroll, J. B., and Bero, L. Industry sponsorship and research outcome. Cochrane Database of Systematic Reviews. 2017; 2. Art. No.: MR000033. doi: 10.1002/14651858.MR000033.pub3

31. Julious, S. A., and Mullee, M. A. Confounding and Simpson's paradox. BMJ. 1994; 309 (6967): 1480-1481. doi:10.1136/bmj.309.6967.1480

32. Ader, F., Peiffer-Smadja, N., Poissy, J., et al. Antiviral drugs in hospitalized patients with COVID19-the DisCoVeRy trial.

doi: https://doi.org/10.1101/2021.01.08.20248149 